\title{
The impact of spinal cord injury on men's time use
}

\author{
W Pentland*,1, AS Harvey ${ }^{2}$, T Smith ${ }^{3}$ and J Walker ${ }^{4}$ \\ ${ }^{1}$ Division of Occupational therapy, School of Rehabilitation Therapy, Queen's University, Kingston, Canada; \\ ${ }^{2}$ Department of Economics, St. Mary's University, Halifax, Canada; ${ }^{3}$ Department of Mathematics \& Statistics, \\ Queen's University, Canada; ${ }^{4}$ Research Department, Westpark Hospital, Toronto, Canada
}

\begin{abstract}
Background: Despite evidence of the relationship between time use and health and well-being, and the World Health Organization's recognition of activity limitation as a measure of disability, there has been limited investigation into the activity patterns of persons with disabilities. Methods: Interviews and time diaries to provide preliminary descriptive and analytical information about the daily time use patterns of men with a spinal cord injury (SCI) living in the community $(n=312)$ compared with the time use data of able-bodied men $(n=3617)$ collected as part of the 1992 Canadian General Social Survey. The study also examined relationships between time use by men with SCI and selected factors (severity of disability and socioeconomic status).

Findings: Statistically different time use patterns between the SCI and able-bodied subjects. The men with spinal cord injury spent on average $7.2 \mathrm{~h}$ in leisure activities (able-bodied men $=6.0 \mathrm{~h}) ; 4.7(7.7) \mathrm{h}$ in productivity; $3.7(2.3) \mathrm{h}$ in personal care; and $8.5(8.0) \mathrm{h}$ sleeping. The SCI men's lesser productivity time was accounted for largely by the lack of time spent in paid work. The average time use of the SCI sample showed the most time spent in passive leisure pursuits such as watching TV and listening to the radio. The sample rated their satisfaction with their time use as mediocre, but levels of adjustment to disability were moderate to high. Regression analysis revealed that severity of disability (lesion level, functional independence, environment) did not predict the amount of time spent in personal care, productivity, leisure, or sleep. Socioeconomic status had a mild predictive relationship with time allocation.

Implications: The findings suggest men with SCI are socially isolated relative to their ablebodied peers. Recommendations are made and include both methodological considerations for further time use studies with persons with SCI, and policy recommendations. The latter focus on the need for rehabilitation, education and resources that go beyond functional independence such that persons with SCI can expand both their leisure and productivity roles and become better socially and economically integrated into society.
\end{abstract}

Keywords: spinal cord injury; time use; activity-patterns; outcomes; adjustment health; wellbeing

\section{Introduction}

The investigation of human's time use patterns dates back to $1924 .^{1}$ As long ago as 1922 , it was recognized that a balanced, varied, and purposeful use of time is both health maintaining and health regenerating. ${ }^{2}$ However, only recently have the relationships between activity patterns, health, and well-being begun to be recognized. ${ }^{3-7,9}$ It has been shown that active involvement and participation in a variety of activities and roles positively affects health and well-being. ${ }^{6,8,9}$ Presumably, if active involvement and participation in a variety of activities and roles has been shown to positively affect health and well-being, it follows that

*Correspondence: W Pentland, Division of Occupational Therapy, School of Rehabilitation therapy, Queen's University, Kingston, ON K7L 3N6, Canada imbalance in activities and roles may precipitate or aggravate problems with health and quality of life. This paper reports on a comparison of time use between men with spinal cord injury (SCI) and a general random sample of Canadian men, in order to shed light on differences in daily routine.

To date, the vast majority of research examining relationships between time utilization and health and well-being is based on the general population. ${ }^{10-13}$ Research exists describing the habitual time use patterns of national populations, ${ }^{10-13}$ as well as for some specific groups such as the elderly, ${ }^{14,15}$ parents, ${ }^{16}$ shift workers, ${ }^{17}$ and to a very limited extent, persons with disabilities. ${ }^{3,7,18,19}$

Chronic illness or severe disability such as SCI can interfere not only with an individual's ability to perform specific tasks, but can also impair his/her 
ability to carry out normal life roles associated with self-care, family, productivity, and leisure. Despite the recognition of activity limitation as a measure of disability, ${ }^{20}$ very little is known about how persons with SCI spend their time, and what the relationship is between their activity patterns (time use) and health and well-being.

Constraints associated with the SCI also likely influence time use, specifically, severity of the disability, functional abilities and the environment. While the few studies available suggest that disability distorts time use patterns, the relationship between severity of disability and time use is not clear. . $^{3,19,21-26}$

The intent of this study was to describe the time use of men with a spinal cord injury living in the community, compare it with that of men without a physical disability, and examine the extent to which selected demographics (income, education, perceived financial stress) and disability factors (lesion level, functional independence, environment) influences the time use of the men with SCI. This study aimed to make new and critical contributions to the present understanding of the disability experience, and how individuals cope.

\section{Methods}

The study design was cross-sectional. Nonparametric descriptive statistics were used to compare time use of the able-bodied and men with SCI since the time use distributions were not normal. Multi linear regression analyses were undertaken to evaluate the influences of selected independent variables (disability severity and socioeconomic status) on the time use of the men with SCI.

\section{Subjects \\ A total of 312 men with spinal cord injury were recruited through the records of Lyndhurst Spinal Cord Centre (LSCC) in central Ontario, Canada. Women were excluded from the sample in recognition of the known influence of gender on time use. Lyndhurst has records for all individuals receiving rehabilitation for SCI over a large geographic area since 1945. The SCI sample met the following selection criteria: age 15 years or more who had no evidence of known cognitive or psychiatric impairment documen- ted on their medical record, and lived in the community. Descriptive statistics for the sample are provided in Table 1. \\ The time use data of the SCI subjects were compared with that of able-bodied men $(n=3617)$ that were collected as part of the 1992 Canadian General Social Survey (GSS7). ${ }^{27}$}

\section{Procedures}

Ethics review and informed subject consents were completed. In recognition of seasonal cyclical changes
Table 1 Descriptive statistics for the two samples

\begin{tabular}{|c|c|c|}
\hline & $S C I(\%)$ & Able-bodied \\
\hline Age (mean (SD)) & $46.5(13.5)$ & not available \\
\hline \multicolumn{3}{|l|}{ Age categories: } \\
\hline $20-39$ years & 39 & 52 \\
\hline $40-59$ years & 42 & 30 \\
\hline 60 years & 19 & 18 \\
\hline \multicolumn{3}{|l|}{ Marital status: } \\
\hline Single & 45 & 33 \\
\hline Partner & 55 & 64 \\
\hline \multicolumn{3}{|l|}{ Educational level: } \\
\hline College/University & 13 & 40 \\
\hline Elem./Sceondary & 87 & 60 \\
\hline \multicolumn{3}{|l|}{ Income: } \\
\hline$<\$ 19000$ & 39 & 31 \\
\hline$\$ 20000-\$ 39999$ & 25 & 40 \\
\hline$>\$ 40000$ & 36 & 29 \\
\hline \multicolumn{3}{|l|}{ Primary mobility: } \\
\hline Wheelchair & 78 & \\
\hline Cane/crutch/walk & 22 & \\
\hline \multicolumn{3}{|l|}{ Lesion levels: } \\
\hline Cervical & 60 & \\
\hline Thoracic & 22 & \\
\hline Lumbar & 18 & \\
\hline $\begin{array}{l}\text { Duration of SCI } \\
(\text { Mean years }(\mathrm{SD}))\end{array}$ & $17.6(11.9)$ & \\
\hline
\end{tabular}

(SCI $n=312$; Able-bodied $n=3617$ )

in human time use, data were collected from the SCI sample $(n=312)$ over three seasons (Winter $n=103$; Summer $n=106$; Fall=103). Data were collected by a combination of telephone interview and mailed questionnaires. Information was collected on the following variables: independent variables: age, income, education, financial stress, lesion level, functional independence, and environment; dependent variables: time spent in self-care, productivity, leisure, sleep, and satisfaction with balance of time use.

\section{Instruments}

The instruments are described below. Prior to analysis, the psychometric performance of the instruments with this sample was checked using factor analysis to confirm unidimensionality, and Cronbach's alpha to confirm internal consistency reliability. Generally, undimensionality was shown to be very high with a range of first factor loadings of $54-76 \%$. Internal consistency reliability for all scales was also good (range $r=0.87-0.97$ ).

Time use: A time diary instrument was developed for this study based on Section D of the 1986 Canadian General Social Survey (GSS), ${ }^{10}$ and the 1992 General Social Survey (GSS) Time Use Survey. ${ }^{27}$ Activities were coded as personal care, leisure, productivity, or sleep according to the classification system used for the 1992 Canadian Time Use Survey. 
Reliability studies have shown that time diaries produce highly replicable and reliable results $(r=0.85-0.92){ }^{28,29}$ In the time use literature, 2 days of data collection are regarded as being more efficient and valid than conducting a single wave of data collection on a larger sample, or data collection over 3 days. ${ }^{30}$ Ziegler and Michaelson ${ }^{31}$ conducted a validity check of time diary data by administering a recall diary the day after systematic observation had taken place. The distribution of time use obtained by the two methods were highly similar, and they concluded that the validity of the time diary was very good.

Satisfaction with balance of time use: This was measured using a 7-point Likert Statement.

Socioeconomic status: This was measured as income, highest level of education and perceived financial stress. Financial stress was measured using the Financial Stress Scale. ${ }^{32}$ This instrument measures the degree of current financial strain in various areas of an individual's life.

Severity of disability: Within the rehabilitation field, the current view of disability is expressed as the extent to which a person's experience of disease or trauma can be characterized by impairment, disability, or restricted social participation. ${ }^{20,33}$ For this study, the disability factor was measured using all three of these aspects of disablement. Impairment was measured as the specific lesion level: disability was measured as functional ability; and, handicap was measured as environment.

Lesion level: This was obtained from the subject's medical record.

Functional ability: This was ascertained using the Functional Independence Measure (FIM) ${ }^{34}$ The FIM is a brief, standardized measure of activities of daily living, used widely in rehabilitation. It results in a percentage score, and normative data are available for a number of populations.

Home, work, and community environments: These were assessed using the short form of Moos' Social Climate Scales. ${ }^{35}$ The social climate of an environment is analyzed according to three dimensions: relationships; personal development; and systems organization. Previous application of the Ward Environment Scale with a spinal cord sample suggested specific item modifications for relevance to the context of disabled people. ${ }^{36}$

\section{Results}

The time use between the samples from the three seasons was tested for differences and no significant differences were found, so for the remaining analyses these data were amalgamated to the final sample of $n=312$ subjects.
Time allocations and comparisons between samples

Table 2 presents the mean time use and standard deviations in hours for the disabled and able-bodied samples, and the results of Mann Whitney U-tests for differences between the two samples. There were statistically significant differences between the two groups for time spent in all four occupational areas (sleep, productivity, leisure, and personal care). The actual differences were the SCI subjects spending on average $1.5 \mathrm{~h}$ more doing personal care; spending approximately $1 \mathrm{~h}$ a day more in leisure; and $3 \mathrm{~h} \mathrm{a}$ day less in productivity related activities than the ablebodied sample. The mean sleep time difference was half an hour greater for those with a disability.

Table 3 represents a finer grained examination of the differences in time allocation between the two groups by comparing the time spent in the subcategories of activities within productivity and leisure. The results of Mann Whitney U-test for differences are also presented. Visual inspection reveals the source of the difference in productivity time lies with paid work, where the able-bodied spent on average $2.7 \mathrm{~h}$ more each day. Similarly, the difference in leisure seems to rest in one sub-category; that being media and

Table 2 Mean hours allocated by the disabled and the ablebodied samples to the four occupational areas $(n=297)$

\begin{tabular}{lccc}
\hline & $\begin{array}{c}\mathrm{n}=297 \\
\text { Disabled } \\
(\bar{x} \text { and }(S D))\end{array}$ & $\begin{array}{c}\mathrm{n}=3617 \\
\text { Able-bodied } \\
(\bar{x} \text { and }(S D))\end{array}$ & P value \\
\hline Sleep & $8.45(1.78)$ & $7.97(1.95)$ & $<0.01$ \\
Personal care & $3.70(1.90)$ & $2.27(1.50)$ & $<0.01$ \\
Productivity & $4.70(3.60)$ & $7.70(4.65)$ & $<0.01$ \\
Leisure & $7.20(3.00)$ & $6.06(3.87)$ & $<0.01$ \\
\hline
\end{tabular}

Table 3 Mean hours allocated by the disabled sample to the sub-categories of activities in productivity and leisure, and results of Mann Whitney U-tests ( $P$ value)

\begin{tabular}{lccccc}
\hline & $\begin{array}{c}\text { Disabled } \\
(\mathrm{n}=297) \\
\text { Hours }(\%) \\
\text { of total } \\
\text { productivity } \\
\text { time }(4.7 \text { h) }\end{array}$ & $\begin{array}{c}\text { Able-bodied } \\
(\mathrm{n}=3617)\end{array}$ & $\begin{array}{c}\text { Hours }(\%) \\
\text { of total } \\
\text { productivity } \\
\text { time }(7.7 ~ h)\end{array}$ & P value \\
\hline Exploded productivity & & & & & \\
Work & 2.4 & $(51.0)$ & 5.13 & $(66.6)$ & $<0.01$ \\
Domestic work & 1.2 & $(25.8)$ & 1.60 & $(20.7)$ & $=0.86$ \\
Education & 0.2 & $(3.7)$ & 0.30 & $(4.0)$ & $=0.18$ \\
Shop & 0.8 & $(17.8)$ & 0.60 & $(8.4)$ & $<0.01$ \\
Child Care & 0.2 & $(3.7)$ & 0.30 & $(3.8)$ & $=0.09$ \\
Adult care & 0.08 & $(1.7)$ & 0.04 & $(0.5)$ & $<0.01$ \\
Exploded leisure & & & & & \\
Communications & 4.5 & $(62.6)$ & 3.2 & $(53.2)$ & $<0.01$ \\
Entertainment & 1.3 & $(18.5)$ & 1.4 & $(23.7)$ & $<0.01$ \\
Sports & 1.1 & $(15.1)$ & 1.0 & $(15.9)$ & $<0.01$ \\
Organized & 0.3 & $(3.8)$ & 0.4 & $(7.2)$ & $=0.15$ \\
\hline
\end{tabular}


communications, with the subjects with SCI spending on average $1.3 \mathrm{~h}$ more time each day.

In an effort to determine the source of the different amounts of time spent in personal care by the two groups $($ disabled $=3.7 \mathrm{~h})$ : able-bodied $=2.3 \mathrm{~h})$, a calculation was made of time spent only on those activities within Personal Care that were exclusively self-care codes (washing, dressing, private activities such as toiletting, and personal medical care performed at home) and these were compared using the Mann Whitney U-test for non-parametric data (due to nonnormal distribution). The disabled spent on average $78 \mathrm{~min}$ in these activities versus the able-bodied spending $40 \mathrm{~min}$, the difference was statistically significant $(P<0.01)$.

The ratio of productivity to leisure is of considerable interest in the disabled population, because of known constraints on both employment and leisure participation. The ratio was compared between the able-bodied and disabled samples and examined according to age, duration of injury and lesion level in the disabled sample. With leisure as the denominator, the average productivity: leisure ratio for the able-bodied sample was 3.2 and the average ratio for the disabled sample was 1.5, illustrating that the ablebodied male spends far more time in productivity activities, than does the male with SCI. Relationships between this productivity: leisure ratio and selected variables (age, lesion level, duration of SCI, satisfaction with balance of activities) were then examined using the Kruskall-Wallis test for independent samples. All were non-significant except for age $(P<0.01)$ in the able-bodied sample.

The second objective of the study was to determine the extent to which the time use of men with a spinal cord injury is influenced by disability severity and socioeconomic factors. The results of multiple linear regression testing of these relationships generated $R^{2}$ values of less than 2 and $P$ values greater than 0.05 in all instances except for the relationship between socioeconomic status and satisfaction with balance of time use. While socioeconomic status (income, education, financial stress) appeared to have no linear predictive relationship to time allocation, it showed a mild linear predictive relationship $\left(R^{2}=14 \%\right.$; $P<0.01)$ with satisfaction with balance of time use.

Table 4 Comparison of mean hours allocated to the four occupational areas by the disabled men $(n=297)$ and Canadians over 65 years $(n=1398)^{15}$

\begin{tabular}{lcc}
\hline & $\begin{array}{c}\mathrm{n}=297 \\
\text { Disabled } \\
(\bar{x})\end{array}$ & $\begin{array}{c}\mathrm{n}=1398 \\
\text { Over } 65 \text { years } \\
(\bar{x})\end{array}$ \\
\hline Sleep & 8.45 & 8.7 \\
Personal care & 3.7 & 4.7 \\
Productivity & 4.7 & 3.1 \\
Leisure & 7.2 & 7.5 \\
\hline
\end{tabular}

The source of the relationship appeared to be mainly education and financial stress. Disability severity (lesion level, functional status, environment) appeared to have no predictive relationship to either SCI subjects' time allocations or satisfaction with balance of time use.

\section{Discussion}

The sample of men with SCI in this study can be considered to have significant physical impairments in that $60 \%$ reported injuries at the cervical level and $78 \%$ use a wheelchair as their primary method of mobility. Fifty per cent of them live with a significant other. Eighty-seven per cent indicate their highest level of education to be elementary or high school. Thirty-eight per cent report they are employed part or full-time.

The time use data for the SCI sample, when examined according to time allocated to the four occupational performance areas (personal care, productivity, leisure, sleep) reveals that other than sleep, they spend on average the most time in leisure $(7.2 \mathrm{~h})$, followed by productivity $(4.7 \mathrm{~h})$ and personal care $(3.7 \mathrm{~h})$. Closer examination of what they do within these latter three categories shows paid work and domestic work to be principal productivity activities. Media and communications (eg, TV, radio, reading) appears to be their major leisure activity; and self-care (toiletting, hygiene, dressing) as a major personal care activity. The mean satisfaction with balance of time allocation in the disabled sample was $4.2 / 7$ which indicates moderately good levels of satisfaction. We do not have comparative data for the able-bodied sample and this would be a useful area for further research.

Based on our findings, living with spinal cord injury distorts activity patterns relative to the able-bodied population, at least as per the Statistics Canada activity classification. While sleep time is similar for the two groups, waking activity patterns differ substantially. Men with spinal cord injury spend $1.5 \mathrm{~h}$ or $39 \%$ more time in the overall category of personal care activities. This is not surprising given their significant disability and presumably greater time required for activities like dressing, bathing and toiletting. Statistical testing revealed the two samples did indeed differ significantly $(P<0.01)$ in the time spent in these specific tasks (wash, dress, medical care at home and private activities). The SCI sample spent on average $78 \mathrm{~min} /$ day on these tasks, versus $40 \mathrm{~min}$ by the able-bodied subjects.

Unlike the present study, Yerxa and Baum Locker ${ }^{7}$ found that SCI subjects spent significantly less time in 'self-maintenance' activities than the able-bodied group. They concluded that this may have been due to the disabled persons receiving help in these areas. They went on to question the assumption that disabled persons will spend more time in self care and less in other activities. ${ }^{7}$ Conversely, our study supports this assumption at least in that the disabled men spent approximately $1 \mathrm{~h}$ per day more on personal care. 
The disabled sample spent on average $1 \mathrm{~h}(20 \%)$ more in leisure or free time activities than the nondisabled men. Closer examination of how they spend their leisure time revealed the primary source of the difference to be the men with SCI spent $1.3 \mathrm{~h}(41 \%)$ more in media/communication activities. These consist of radio, TV, reading, telephone conversation and letters. The difference suggests that the men with SCI spend more time in relatively physically inactive leisure pursuits and activities that typically have lower associated participation expenses.

Time spent in productive activity revealed the greatest differences between the two samples. The men with SCI spent $3 \mathrm{~h}$ or $40 \%$ less time in productivity related activities. Examination of the subcategories revealed the source of this difference to like almost exclusively in paid work, with the SCI sample spending $2.7 \mathrm{~h}$ or $53 \%$ less time in paid work. It is difficult to know with certainty what is the reason for the SCI sample's lesser time spent in paid work. It may be in part a reflection of the disability itself and associated physical limitations. The SCI sample in this study had generally fewer years of formal education than their able-bodied couterparts, which may disadvantage them in finding employment. For persons with disabilities, obtaining and holding on to work for pay is a complex phenomenon that results from an interaction of their impairment (physical abilities), demographic characteristics and environmental factors such as availability of suitable work, access, transportation and societal attitudes. Interestingly, despite less time in paid work, the income distribution revealed similar household incomes between the two samples. The SCI sample's results on the Financial Stress scale indicate that they feel moderate levels of financial stress. We do not have similar financial stress information for the able-bodied sample.

In hours then, we have a daily activity picture of men with a spinal cord injury that differs significantly from that of their able-bodied counterparts. The differences seem to be that the men with SCI spend less than half of the time in paid work than do the able-bodied males, and that this non-working time is taken up by self-care activities, and leisure activities, particularly media/communication activities. These results suggest men with SCI are socially isolated relative to their able-bodied peers, and may require practical and financial supports including skill training to enable improved community integration in the areas of productivity and leisure.

Studies comparing the time use of persons with and without disability are rare. The existing research suggests that disability negatively impacts on time use in terms of decreased frequency of activities, ${ }^{3,22,37,38}$ higher unemployment, ${ }^{39-41}$ and altered time allocation compared to the general population. ${ }^{4-44}$ Persons with disabilities have also been shown to experience decreased satisfaction with their performance of activities. ${ }^{7,39,42}$
Yerxa and Baum Locker, ${ }^{7}$ also focusing on persons with SCI, compared the time use between two very small samples of $15 \mathrm{SCI}$ men and women with 12 ablebodied men and women. In contrast to the present study, the majority of their subjects were educated beyond the high school level. Employment and income demographics and disability severity were similar to those in this study. Our findings on time allocation are very similar to those of Yerxa and Baum Locker ${ }^{7}$ with other than sleep, the highest amounts of time being spent in leisure and mass media activities, and much less time spent in productivity-related activities than the non-disabled group.

The SCI sample's average ratio of time spent in leisure/productivity was $1.5 \mathrm{~h}$. The greater amount of time spent in leisure versus productivity may be a result of a number of factors. We know that lower education levels limit employment potential, particularly in certain fields. This plus their significant levels of impairment may be excluding them from jobs that able-bodied persons with similar levels of education can normally access (eg, more physical jobs such as the trades). While desire to find paid work was not measured in this study, it should be considered that the group's lower levels of education may indicate they need job training or skill upgrading in order to open up job possibilities in the less physically demanding fields (eg, computing; desk-type work).

The sample's participation in productive activities may also be limited by physical limitations that accompany particularly those with cervical level injuries, such as reduced endurance, reduced health status in general, and limited mobility requiring the use of a wheelchair. Individuals with these types of constraints require accommodations to enable productivity that include flexible work schedules, barrier free access to permit wheelchair use, ergonomic workstation design, positive employer and fellow employee attitudes, and readily available transportation.

Similar factors may explain the leisure time profile of the sample, those being physical limitations, inaccessibility, and limited skill levels. In addition, cost may be a limiting factor. The group reported moderate levels of perceived financial stress, with close to $40 \%$ having a household income of less than $\$ 19000$ /annum which is low considering the added costs of living with a significant disability (wheelchair and equipment, attendant assistance, accessible transportation).

The SCI group spends close to $65 \%$ of its leisure time $(4.5 \mathrm{~h} /$ day $)$ in media/communication activities (watching television/videos, listening to radio/music, and reading). These activities have very low participation expenses in that they occur in the home and require generally inexpensive equipment. They are also physically very sedentary pursuits. This tendency to a more inactive lifestyle has been borne out by other studies of disabled men ${ }^{45}$ disabled children, ${ }^{3}$ persons with mental illness, ${ }^{18}$ and spinal cord injured men. ${ }^{7}$

While the physically sedentary nature of these leisure activities intuitively seems an appropriate 
adaptation to high levels of physical impairment, it may be that the lack of physical activity and social contact is counter-productive to both the subjects' physical and emotional well-being. Leisure time generally is defined as time spent as one chooses and can be an important opportunity for socialization, to reduce stress, express one's self and to maintain or improve physical fitness. There is ample literature on the importance of maintaining physical conditioning throughout the lifespan for both able-bodied and persons with a disability. Furthermore, while participation in passive activity by this group to an extent may be viewed as adaptive, in the extreme it may be maladaptive in that it will interfere with routines and roles that are normal for that individual.

Age and time use in the elderly able-bodied Canadian population $(n=1398)$ was examined by McKinnon ${ }^{15}$ who showed the Canadian over 65 year-old group to allocate their time similarly to the present younger SCI sample (see Table 4). In fact the time distributions between the two samples are strikingly similar. Furthermore, McKinnon ${ }^{15}$ reported that the elderly also spent the vast majority of their leisure time on media and communication, particularly watching television. While this narrower leisure repertoire may be developmentally appropriate for the elderly population it is atypical for the younger population and one wonders as to the impact of such as 'old person's' leisure profile on a younger person with a SCI. The similarity of the time use profile between the two groups is remarkable and suggests that the men with SCI are somewhat socially isolated for their age.

Two broad areas of potential influence that we did not examine and which may be particularly influential are individual's psychological/spiritual characteristics and broad environmental factors (physical and sociocultural). In fact, given the consistency of our findings of lack of predictive relationships in the variables examined, it seems highly advisable that psychological/ spiritual and environmental characteristics should be examined in future research.

\section{Conclusions}

Daily activity patterns reflect peoples' integration and participation in society. This study revealed that time allocation of men with spinal cord injury differs profoundly from that of similar aged men in the able-bodied population, and suggests that men with moderate to severe levels of physical impairment lead a life dominated by inactive leisure pursuits, limited productive activities, and appear to be socially isolated for their age. The finding that severity of SCI has no linear predictive relationship to time spent in productivity activities reinforces the view that social participation of persons with disabilities is not so much a function of the degree of impairment but of other factors, many of which reside in the environment. These can include available social support, education, individual personality/psychological factors, and societal attitudes.

\section{Acknowledgements}

The authors gratefully acknowledge the financial support of the Canadian National Health Research Development Program (NHRDP - 6606-5005-101).

\section{References}

1 Andorka R. Time budgets and their uses. Annals of Reviews in Sociology 1987; 13: 149-164.

2 Meyer A. The philosophy of occupational therapy. Archives of Occupational Therapy 1922; 1: 1-10.

3 Brown M, Gordon W. Impact of impairment on activity patterns of children. Archives of Physical Medicine of Rehabilitation 1987; 68: $828-832$

4 Lawton M, Moss M, Fulcomer M. Objective and subjective uses of time by older people. International Journal of Aging and Human Development 1986-87: 24: 171-188.

5 Hasselkus B. The meaning of daily activity in family caregiving for the elderly. American Journal of Occupational Therapy 1989; 43: $649-656$

6 Fidler GS, Fidler JW. Doing and becoming: Purposeful action and self-actualization. American Journal of Occupational Therapy 1978; 32: $305-310$.

7 Yerxa E, Baum S. Quality of time use by adults with spinal cord injuries. American Journal of Occupational Therapy 1990; 44: $318-326$.

8 Kielhofner G. The conceptual foundations of occupational therapy. Philadelphia: F.A. Davis, 1992.

9 Szalai A. Quality of life and the individual use of time. Paper presented at Conference Fundacion. Bariloche, Argenina, 1980.

10 Harvey A, Marshall J, Frederick J. Where does time go? Ottawa: Statistics Canada: Catalogue \#11-612-No.4, 1991.

11 Belloni MC. National Survey on time use in Italy. International Association for Time Use Research, 11th World Congress, International Sociological Association, Madrid, Spain, June 1990.

12 Niemi I, Paakkonen H. Time Use Changes: In Finland in the 1980's. Helsinki: Central Statistical Office of Finland, 1990.

13 Hanslow B. Information paper: Time use pilot survey. Sydney: Australia Bureau of Statistics, Catalogue No. 4111.1, 1988.

14 Baltes M, Wahl H, Schmid-Furstoss U. The daily life of elderly Germans: Activity patterns, personal control, and functional health. Journal of Gerontology 1990; 45: 173-179.

15 McKinnon AL. Time use for self-care, productivity, and leisure among elderly Canadians. Canadian Journal of Occupational Therapy 1992; 59: $102-110$.

16 Hermann C. A descriptive study of daily activities and role conflict in single adolescent mothers. Occupational Therapy in Health Care Haworth Press Inc: Los Angeles, 1990, pp 53-68.

17 Rosenthal L, Howe M. Activity patterns and leisure concepts: A comparison of temporal adaptation among day versus night shift workers. Occupational Therapy in Mental Health 1984; 4: 59-78.

18 Larson K. Activity patterns and life changes in people with depression. The American Journal of Occupational Therapy 1990; 44: $902-906$.

19 Osberg JS, McGinnis GE, DeJong G, Seward ML. Life satisfaction and quality of life among disabled elderly adults. Journal of Gerontology 1987; 42: 228-230.

20 World Health Organization (WHO). International classification of impairments, disabilities, and handicaps. Geneva: World Health Organization, 1980.

21 Morgan D, Jongbloed L. Factors influencing leisure activities following a stroke: An explanatory study. Canadian Journal of Occupational Therapy 1990; 57: $223-228$.

22 McDonald M, Nielson W, Cameron M. Depression and activity patterns of spinal cord injured persons living in the community. Archives of Physical Medicine and Rehabilitation 1987; 68: 339 343. 
23 DeJong G. Independent living: From social movement to analytic paradigm. Archives of Physical Medicine and Rehabilitation Research 1979; 60: $435-446$

24 Nosek MA, Parker RM, Larsen S. Psychosocial independence and functional abilities: Their relationship in adults with severe musculo-skeletal impairments. Archives of Physical Medicine and Rehabilitation 1987; 68: $840-845$.

25 Dowler JM, Jordan-Simpson DA. Participation of people with disabilities in selected activities. Health Reports 1990; 2: $269-$ 277.

26 Lifshez R. The environment as a support system for independent living. Archives of Physical Medicine and Rehabilitation Research 1979; 60: $467-476$

27 Statistics Canada. Initial Data Release from the 1992 General Social Survey on Time Use. Statistics Canada: Ottawa, 1993.

28 Robinson JP. The validity and reliability of diaries versus alternative time use measures. In: Juster F, Stafford F (eds). Time, Goods, and Well-being Chapter 3. Ann Arbor: Survey Research Centre, Institute for Social Research, University of Michigan, 1985.

29 Robinson JP. Changes in Americans' use of time. 1965-1975 - A progress report. Cleveland, Ohio: Communication Research Centre, Cleveland State University, 1977.

30 Pas I. Sample design, parameter estimation, efficiency, and data collection costs for least square regression trip generation models. Paper prepared for the 1985 Annual Transportation Research Board Meeting, USA 1984.

31 Ziegler S, Michaelson W. Complimentary methods of data gathering in literate, urban populations. Human Organization 1981; 40: 323 - 329 .

32 Feather NT. Financial stress scale. In: Feather NT (ed). The Psychological Impact of Unemployment. 1989.

33 Canadian Society for the International Classification of Impairments, Disabilities and Handicaps (CSICIDH). The Handicaps Creation Process. CSICIDH: Quebec City, 1991.

34 Keith RA, Granger CV, Hamilton BB, Sherwin FS. The functional independence measure: A new tool for rehabilitation. In: Eisenber MG, Grzesiak RG (eds). Advances in Clinical Rehabilitation. New York: Springer, 1987, pp. 107-121.
35 Moos R. Evaluating correctional and community settings. New York: John Wiley and Sons, 1975.

36 Day H, Clarke L. Discrepancies in the perception of the Lyndhurst Environment. 1991. Unpublished Report.

37 Trieschmann R. Aging with a Disability. New York: Demos Publications 1987.

38 Trieschmann R. Spinal cord injuries: Psychological, social, and vocational rehabilitation. 2nd edn. New York: Demos Publications 1988.

39 Yerxa E, Baum S. Engagement in daily occupations and life satisfaction among people with spinal cord injuries. The Occupational Therapy Journal of Research 1986: 6: 272 - 283.

40 Danek MM, Lawrence RF. Women in rehabilitation: An analysis of state agency services to disabled women. Journal of Applied Rehabilitation Counselling 1985; 15: 16-18.

41 Niemi I. Time use of the disabled in Finland. Paper presented at the International Research Meeting on the Relationships Between Time Use and Health, Well-being, and Quality of Life. Queen's University, Kingston, Canada, 1993.

42 Dowler JM, Jordan-Simpson DA. Participation of people with disabilities in selected activities. Health Reports 1990; 2: $269-$ 277.

43 Kraus JS, Crewe N. Prediction of longterm survival among persons with spinal cord injury: An 11 year prospective study. Rehabilitation Psychology 1987; 32: 205-213.

44 Gordon WA. Psychological adjustment and characteristics in recent spinal cord injuries. Final Report to National Institute of Handicapped Research. Department of Education Grant, 13-P59127, 1982.

45 Brown MM. Actual and perceived differences in activity-patterns of able-bodied and disabled men. New York University Dissertation Abstracts International 1982; 43: 2314-B. 